\title{
Letter
}

\section{Response to Comment by T. SCAMBOS and C. SHUMAN (2016) on 'Mass gains of the Antarctic ice sheet exceed losses' by H. J. Zwally and others (2015)}

Scambos and Shuman (2016) state: 'This need for an improved understanding (of ice mass balance) extends beyond the glaciological community and includes policy makers and the general public.' For this reason, we believe it is important as scientists to make our best efforts to provide the most accurate results, and not merely accept previously published results without critical evaluation. Scambos and Shuman' assert that our 'result .... is inconsistent with a large body of previously published work' and that 'The.... conclusion is clearly an outlier among recent studies of Antarctic mass balance.' They base their assertions on a selective overview of previously published work, ignoring papers that do not agree with their view, overlooking uncertainties in prior work, and not recognizing the need for continued improvement. They rely heavily on the Ice Mass Balance Intercomparison Exercise (IMBIE) (Shepherd and others, 2012), which they say 'was a reconciliation of nearly all high quality mass balance estimates at that time'. However, IMBIE simply took the mean of selected estimates and did not actually reconcile significant differences in the sense of investigating or explaining their causes. An important review paper not mentioned by Scambos and Shuman' is Hanna and others (2013) that reviewed the progress following IMBIE, discussed the remaining uncertainties and likely causes, and recommended additional research, especially for East Antarctica (EA).

We fully believe our paper represents an advancement in scientific knowledge, based on rigorous analysis and reduction of uncertainties. We continue to have high confidence in our results and conclusions. We carefully considered prior work in relation to ours and provided reasons why our results differed from key other papers. Overall, we believe the concerns expressed by Scambos and Shuman' would have been substantially alleviated by a thorough reading of our paper with attention to the scientific and technical details we provided about our methodologies, the arguments we made, the supporting analyses, and our supporting references to other peer-reviewed literature.

Our results are in essential agreement with other studies that show an increasing mass loss in the Antarctic Peninsula and the Thwaites and Pine Island region of West Antarctica (WA), where large changes are observed over relatively small areas, but differ in the interior of West Antarctica (WA2) and EA, where the changes are small over large areas. Very importantly, Scambos and Shuman' fail to recognize the significance of our ERS-1/ERS-2 results for EA and their very close agreement with our ICESat results, both in general over their common observation region north of $81.5^{\circ} \mathrm{S}$ and in particular over Lake Vostok. Previous unrefuted results based on ERS-1 and ERS-2 showing ice-sheet growth in EA include: Wingham and others (1998); Davis and others (2005); Zwally and others (2005), and Wingham and others (2006). In particular,
Davis and others' found: 'Using a near-surface snow density of $350 \mathrm{~kg} \mathrm{~m}^{-3}$, an average elevation change of 1.8 $\pm 0.3 \mathrm{~cm} \mathrm{a}^{-1}$ (from ERS-1/ERS-2 radar altimeter data) over an area of 7.1 million $\mathrm{km}^{2}$ for the EA interior (Table S1) corresponds to a mass gain of $45 \pm 7 \mathrm{Gt} \mathrm{a}^{-1}$; their corrected result would be $117 \pm 18 \mathrm{Gta}^{-1}$ using the appropriate density of ice, because the increase in elevation has been shown to not be from increasing snowfall. Furthermore, the accuracy of ERS-1/ERS-2 altimetry for constructing time series is demonstrated by its measurement of global sealevel rise in good agreement with TOPEX and other ocean radar altimeters at the rate of $2.7 \mathrm{~mm} \mathrm{a}^{-1}$ (Scharroo and others, 2013).

Scambos and Shuman' assert that the ICESat data are not accurate, but provided no valid evidence to support their assertions. Their critique of ICESat accuracy is based on questions about the ICESat inter-campaign biases and the GLAS saturation corrections. However, they do not recognize the advantages of our well-documented methodology (in numerous peer-reviewed papers) for determining the biases to the ocean level in the Arctic and Antarctic sea-ice packs, including accounting for changes in the ocean level independently measured by Envisat radar altimetry. We applied the latest refined and accurate saturation range corrections that have been available on the GLAS data products at NSIDC since 2012, but need to be applied to the products by the users. However, Scambos and Shuman' apparently have not updated their analysis of the saturation errors over Lake Vostok using those more accurate corrections (See Supplemental Material (SM)).

Scambos and Shuman' argue that we differ from other 'recent' studies, especially for EA. In our paper (in particular the last three paragraphs of Results and Discussion; Zwally and others, 2015), we discuss principal reasons why we believe other results differed from ours, noting likely deficiencies in methodologies. Regarding the IMBIE differences in EA, we noted: 'In contrast, for EA the reconciled mean of $+24 \pm 36 \mathrm{Gt} \mathrm{a}^{-1}$ contained the means and most of the ranges of only the radar altimetry (RA) and gravity (GR) results. The EA mean from Input/Output Method (IOM) was more negative at $-30 \pm 76 \mathrm{Gt} \mathrm{a}^{-1}$ and the mean from laser altimetry (LA) was more positive at $+109 \pm 57 \mathrm{Gta}^{-1}$. Variations among the LA estimates were due to different methods of estimating $\mathrm{d} M / \mathrm{d} t$ from $\mathrm{d} H / \mathrm{d} t$, differing choices for the ICESat intercampaign biases, differing methods of $\mathrm{d} h / \mathrm{d} t$ solutions, and different data-editing procedures, which have been improved for our EA mass gain of $+136 \pm 28 \mathrm{Gt} \mathrm{a}^{-1}$.

Technical reasons for differences included: 'Possible causes for the lower (IMBIE) RA estimate of $+22 \pm 39 \mathrm{Gt} \mathrm{a}^{-1}$ for EA are inadequate corrections to the Envisat data for variable radar penetration depth (as discussed in the Appendix) and the use of a low (relative) density of 0.35 to estimate $\mathrm{d} M / \mathrm{d} t$ from $\mathrm{d} H / \mathrm{d} t$ assuming the changes were due to snowfall anomalies (as discussed in Section 4). A likely cause for the lower GR estimate is the sensitivity of the GR estimates to the glacial isostatic adjustment (GIA) correction, as discussed in the Appendix where we note that a $-1.6 \mathrm{~mm} \mathrm{a}^{-1}$ change in the modeled $d B / d t$ would bring the GR and our $\mathrm{d} M / \mathrm{d} t$ into agreement at approximately $+150 \mathrm{Gt} \mathrm{a}^{-1}$.' 
Figure 1 of Scambos and Shuman', with its nine GRACE gravimetry results, three altimetry results, and the IMBIE 'consensus' average result, should be compared with the similar (but more comprehensive and informative) Fig. 1 of Hanna and others (2013) that separated pre-2012 studies from 2012 studies. The separation showed the evolution toward results that are more-narrowly distributed between +100 and $-100 \mathrm{Gt} \mathrm{a}^{-1}$, with the deletion of earlier more negative values (except for the more negative IOM, 'Mass Budget' results). In particular, Hanna and others' reviewed the advances in modeling of the GIA (caused by the motion $\mathrm{d} B / \mathrm{d} t$ of the underlying bedrock) that have led to a reduction in GIA uncertainties in GRACE estimates and closer agreement with altimetry results. As we discussed, gravimetry results are approximately six times more sensitive to errors in $\mathrm{d} B / \mathrm{d} t$ than altimetry results. Hanna and others' also note: 'However, several key challenges remain. First, changes in ice extent and thickness during the past millennium are poorly known, and typically not included in GIA models, despite the fact that they can dominate the present-day rebound signal, especially in regions of low mantle viscosity'. In our paper, we said: 'The additional ice loading from a dynamic thickening of $1.59 \mathrm{~cm} \mathrm{a}^{-1}$ over EA (Table 2) for $10 \mathrm{ka}$ implies an additional bedrock depression of $27 \mathrm{~m}$ continuing at a rate of $2.65 \mathrm{~mm} \mathrm{a}^{-1}$ assuming full long-term isostatic adjustment. Therefore, the $-1.6 \mathrm{~mm} \mathrm{a}^{-1}$ needed to bring the gravimetry and altimetry $\mathrm{d} M / \mathrm{d} t$ estimates into agreement is only $60 \%$ of the full isostatic adjustment rate, and therefore within the range of what can be expected if the ice loading implied by the long-term dynamic thickening is accounted for in the GIA models.' Therefore, a common error in the GIA correction to the nine GRACE results is a distinct possibility needing further investigation.

The other two altimetry-based results (Helm and others, 2014; McMillan and others, 2014) in Fig. 1 of Scambos and Shuman' are based on CryoSat radar-altimeter data with issues regarding: (1) the estimated density used to derive mass changes; (2) the accuracy of linear trends derived from only 3 a of data; and (3) the reliability of corrections made for the highly variable penetration of the radar signal into the firn. As described in Rémy and others (2012), the penetration depth is strongly dependent on the orientation of the linearly polarized radar signal relative to the anisotropy of the scattering properties of the firn, which causes systematic elevation biases at orbital crossovers (see SM). McMillan and others' apply a 'backscatter' correction (without details), and Helm and others' simply add a random uncertainty of $0.5 \mathrm{~m}$ to their error estimate. Also, Helm and others' might not have applied the G/C correction.

Scambos and Shuman' state: 'In fact, observed EAIS velocities are $80 \%$ of the balance velocities in recent estimates (van Wessum and others, 2014).' However, their implied imbalance of $\sim 20 \%$ is not inconsistent with our estimate of $\sim 13 \%$. As we stated: 'A residual thickening from the Holocene increase in accumulation is consistent with the characteristic slow response time of the ice flow to accumulation changes in EA. Comparing the $147 \mathrm{Gt} \mathrm{a}^{-1}$ dynamic gain with $\mathrm{SMB}$ gives a current residual dynamic imbalance of $\sim 13 \%$ '. 'In the interior areas of the ice sheet, dynamic response times are much longer than in the higher accumulation and thinner areas closer to the coastal margins. For example, in the interior of EA where the accumulation is low (e.g. $0.03 \mathrm{~m} \mathrm{a}^{-1}$ ) and the ice is thick (e.g. $2500 \mathrm{~m}$ ), the ice thickness increase over $10 \mathrm{ka}$ (for a doubling of accumulation) is only $\sim 300 \mathrm{~m}$. The corresponding fractional increase in driving stress over that time is only $\sim 12 \%$, implying the flow takes a very long time to adjust to the change.' $\mathrm{A}$ more appropriate description of the long-term time-dependent behavior is given by a 3-D ice-sheet model incorporating anisotropic ice flow and fully coupled dynamics and thermodynamics (Wang and others, 2012), which showed a presentday thickening rate of $2.5 \mathrm{~cm} \mathrm{a}^{-1}$ in central EA resulting from an step increase from $40 \%$ of present-day accumulation rates to present-day values $10 \mathrm{ka}$ ago (Wang and others, 2013). The modeled $2.5 \mathrm{~cm} \mathrm{a}^{-1}$ thickening rate was nearly linear over the last $10 \mathrm{ka}$ causing a thickness increase of $250 \mathrm{~m}$ at present, followed by a decreasing rate of thickening to an asymptotic thickness increase of $400 \mathrm{~m}$ in another $40 \mathrm{ka}$.

Scambos and Shuman' assert: '... few EAIS interior areas... actually show similar trends... the ERS trend oscillates around $0 \mathrm{~cm} \mathrm{a}^{-1}$, and is generally lower than... ICESat trend. South of $81.5^{\circ}$ S, Zwally 2015 use only the ICESatbased estimate... increasing the dependence of... conclusions on... ICESat... '. The ERS and ICESat data have similar trends in $\mathrm{d} H / \mathrm{d} t$ over $\mathrm{EA}$, and essentially identical trends in the dynamic component $\mathrm{d} H_{\mathrm{d}} / \mathrm{d} t$, neither of which 'oscillate around $0 \mathrm{~cm} \mathrm{a}^{-\gamma^{\prime}}$. Over all of EA (our Table 2), the average $\mathrm{d} H / \mathrm{d} t$ from ERS and ICESat are 1.11 and $1.30 \mathrm{~cm} \mathrm{a}^{-1}$ and the $\mathrm{d} H_{\mathrm{d}} / \mathrm{d} t$ are 1.58 and $1.59 \mathrm{~cm} \mathrm{a}^{-1}$. Over the common observation area north of $81.5^{\circ} \mathrm{S}$, the respective $\mathrm{d} H / \mathrm{d} t$ averages are similar at 1.07 and $1.31 \mathrm{~cm} \mathrm{a}^{-1}$ and the $\mathrm{d} H_{\mathrm{d}} / \mathrm{d} t$ are 1.44 and $1.69 \mathrm{~cm} \mathrm{a}^{-1}$. Therefore, our conclusions for the common area would be essentially the same as for all of EA.

Scambos and Shuman' fail to recognize the critical importance of our advanced methodology for deriving accurate mass changes $(\mathrm{d} M / \mathrm{d} t)$ from measured elevation changes $(\mathrm{d} H /$ $\mathrm{d} t$ ). We compared our methodology with the outdated methodology of simply guessing a value of the relative density $\left(\rho_{\mathrm{g}}\right)$ to calculate $\mathrm{d} M / \mathrm{d} t=\rho_{\mathrm{g}} \cdot \mathrm{d} H / \mathrm{d} t$, where $\rho_{\mathrm{g}}$ may range by a factor of three from 0.3 for compacted snow to 0.91 for solid ice. Our calculations for various density definitions in Table 4 illustrate the impossibility of choosing a valid single value of $\rho_{\text {g }}$ to estimate $\mathrm{d} M / \mathrm{d} t$ from $\mathrm{d} H / \mathrm{d} t$. The primary reason a valid $\rho_{\mathrm{g}}$ cannot be chosen is that the measured $\mathrm{d} H / \mathrm{d} t$ are highly-variable combinations of accumulation-driven elevation change $\left(\mathrm{d} \mathrm{H}_{\mathrm{a}} / \mathrm{d} t\right)$, for which the relative density $\left(\rho_{\mathrm{a}}\right)$ ranges from 0.2 to 0.91 with an average of 0.39 as shown in our Fig. 8, and dynamic-driven changes $\left(\mathrm{d} H_{\mathrm{d}} / \mathrm{d} t\right)$, for which the appropriate relative density $\left(\rho_{\mathrm{i}}\right)$ is 0.91 . In addition, the values are often of opposite sign at the same location.

Overall, our results and conclusions provide new evidence on changes in the mass balance of Antarctica over the last two decades. When combined with evidence of accumulation increases that commenced $10 \mathrm{ka}$ ago, we concluded that long-term thickening in EA is continuing to have a small beneficial impact on the current rate of global sea-level rise. At present, the long-term mass increase in EA continues to offset the recent marked increases in mass loss observed in WA and the AP. Important questions for continued research include: how fast will climate-induced increases in dynamic thinning proceed, and how might future increases in precipitation with climate warming provide additional offsets.

\section{SUPPLEMENTARY MATERIAL}

The supplementary material for this article giving additional specifics regarding: (1) Saturation Corrections, (2) ICESat 
Inter-campaign Biases, (3) G-C Correction, (4) Radar-Backscatter Correction and (5) Miscellaneous points including the Scambos and Shuman' references to media coverage can be found at http://dx.doi.org/10.1017/jog.2016.91.

\section{ACKNOWLEDGEMENTS}

We very much appreciate the insightful comments and suggestions of an anonymous reviewer, the numerous engineers and scientists dedicated to the success of the ICESat mission, and the continued support of NASA management.

${ }^{1}$ Cryospheric Sciences Laboratory, NASA Goddard Space Flight Center, Greenbelt, MD, USA, ${ }^{2}$ Earth System Science Interdisciplinary Center, University of Maryland, College Park, MD, USA, ${ }^{3} S G T$, Inc., NASA Goddard Space Flight Center, Greenbelt, MD, USA, ${ }^{4}$ Craig Technologies, NASA Goddard Space Flight Center, Greenbelt, MD, USA, ${ }^{5}$ Science Systems and Applications, Inc., NASA Goddard Space Flight

Center, Greenbelt, MD, USA

${ }^{6}$ Sigma Space Corporation, Lanham, $M D, U S A$

E-mail: H. Jay Zwally <jayzwallyice@verizon.net>

\section{REFERENCES}

Davis CH, Li Y, McConnell JR, Frey MM and Hanna E (2005) Snowfall-driven growth in East Antarctic ice sheet mitigates recent sea-level rise. Science, $\mathbf{3 0 8}$

Hanna E and 11 others (2013) Ice sheet mass balance and climate change. Nature, 498 (doi: 10.1038/nature12238)
Helm V, Humbert A and Miller H (2014). Elevation and elevation change of Greenland and Antarctica derived from CryoSat-2. Cryosphere, 8, 1539-1559 (doi: 10.5194/tc-8-1539-2014)

McMillan M and 7 others (2014) Increased ice losses from Antarctica detected by CryoSat-2. Geophys. Res. Lett., 41 (doi: 10.1002/ 2014GL060111)

Rémy F, Flament T, Blarel F and Benveniste J (2012) Radar altimetry measurements over Antarctic ice sheet: a focus on antenna polarization and change in backscatter problems. $A d v$. Space Res., $\mathbf{5 0}$

Scambos T and Shuman C (2016) Comment on Mass Gains of the Antarctic Ice Sheet exceed Losses by H. J. Zwally and others. J. Glaciol. (doi: 10.1017/jog.2016.59)

Scharroo R and 5 others (2013) RADS: Consistent multi-mission products, in Proc. Symp. on 20 Years of Progress in Radar Altimetry, Venice, 20-28 September 2012, European Space Agency Specification Publ., ESA SP-710, p. 4 pp

Shepherd A and 46 others (2012) A reconciled estimate of ice-sheet mass balance. Science, 338, 1183-1189.

Wang W, Li J and Zwally HJ (2012) Dynamic inland propagation of thinning due to ice loss at the margins of the Greenland ice sheet. J. Glaciol., 58(210), 734-740 (doi: 10.3189/ 2012JoG11J187)

Wang W, Li J and Zwally HJ (2013) Modeling dynamic thickening in East Antarctica as observed from ICESat, Abstract C53B-0571 presented at 2013 Fall Meeting, AGU, San Francisco, California, 9-13 December

Wingham DJ, Ridout AL, Scharroo R, Arthern RJ and Shum CK (1998) Antarctic elevation change 1992 to 1996. Science, 282 (5388), 456-458.

Wingham DJ, Shepherd A, Muir A and Marshall GJ (2006) Mass balance of the Antarctic ice sheet. Philos. Trans. R. Soc. A, Math. Phys. Eng. Sci., 364, 1627-1635 (doi: 10.1098/ rsta.2006.1792)

Zwally HJ and 7 others (2005) Mass changes of the Greenland and Antarctic ice sheets and shelves and contributions to sea-level rise: 1992-2002. J. Glaciol., 51(175), 509-527 (doi: 10.3189/ 172756505781829007)

Zwally HJ and 5 others (2015) Mass gains of the Antarctic ice sheet exceed losses. J. Glaciol., 61(230), 1019-1035 (doi: 10.3189/ 2015JoG15J071) 